\title{
DE PRINCESAS A SUPER-HERÓIS: A INFLUÊNCIA DOS PERSONAGENS NA ALIMENTAÇÃO E EDUCAÇÃO DAS CRIANÇAS ${ }^{1}$
}

\author{
FROM PRINCESSES TO SUPERHEROES: THE INFLUENCE OF THE \\ CHARACTERS IN THE FEEDING AND EDUCATION OF CHILDREN
}

\section{Eliane Dominico ${ }^{2}$ Aliandra Cristina Mesomo Lira ${ }^{3}$}

RESUMO: O objetivo central desse texto é problematizar a relação entre mídia, consumo e alimentação infantil, buscando reconhecer quais as preferências das crianças e como essas orientam suas escolhas alimentares. A partir das reflexões de autores como Horn (2016), Schor (2009) e Baader (2013), dentre outros, fizemos uma coleta de dados por meio de entrevista-conversa com grupos de escolares, a partir de um roteiro semiestruturado. Observou-se que os produtos que as crianças querem comprar e consomem fazem parte do campo de desejos dos pequenos, construído principalmente pela associação entre o alimento e imagens de personagens conhecidos. Frente aos estudos teóricos e os resultados de pesquisa, ressaltamos a importância de refletir acerca da inconteste relação de consumo de alimentos pelas crianças e a articulação das grandes empresas de publicidade, do setor alimentício e do entretenimento.

PALAVRAS-CHAVE: alimentação infantil, consumo, publicidade.

ABSTRACT: The central goal of this text is to problematize the relationship between media, consumption and alimentation of children, looking to recognize the preferences of children and how they orient their food choices. Based on the reflections of authors such as Horn (2016), Schor (2009), Baader (2013) and others, data was collected through interview and conversation with school groups, following a semistructured outline. It was observed that the products children wanted to buy and consume were part of their desire field, built specially through the association

\footnotetext{
${ }^{1} \mathrm{O}$ artigo em questão decorre de reflexão em disciplina de curso de mestrado, com foco na educação empreendida pela publicidade e pelos personagens conhecidos do público infantil, ou seja, uma educação que não se dá nos limites da escola, mas por meio dos mais variados artefatos colocados em circulação pela indústria cultural.

${ }^{2}$ Mestranda em Educação. Universidade Estadual do Centro-Oeste. Professora da rede Municipal de ensino da cidade de Guarapuava. Guarapuava/Paraná/Brasil.nane_dominico@hotmail.com

${ }^{3}$ Doutora em Educação. Professora do Departamento de Pedagogia e do Programa de Pós-Graduação em Educação da Universidade Estadual do Centro-Oeste. Guarapuava/Paraná/Brasil. aliandralira@gmail.com
}

Rev. Fac. Educ. (Univ. do Estado de Mato Grosso), Vol. 28, Ano 15, № 2 p. 113-127, jul./dez. 2017 
between the food and the character known. Facing theoric studies and research results, we emphasized the importance of reflecting about the uncontested relationship of food consumption by children and the articulation of big publicity companies, those being from the food sector as well as the entertainment sector.

KEYWORDS: alimentation of children, consumption, publicity.

\section{Introdução}

Comer é um ato social, com significados e encaminhamentos diversos em cada cultura. Comemos quando estamos com amigos, em família, para compartilhar momentos, quando estamos alegres e também há aqueles que comem mais quando estão tristes. Assim, comer alimenta o corpo e a alma. Para a criança pequena, a experiência com a alimentação começa já ao nascer, e pouco a pouco vai incorporando as interferências do contexto onde vive (PIOTTO; FERREIRA; PANTONI, 2016).

$\mathrm{Na}$ atualidade, nos grandes centros urbanos, a alimentação das crianças e suas famílias tem sido moldada pela produção das indústrias, que em associação com a mídia divulgam seus produtos e estimulam os desejos e o consumo. Mais especificamente com relação à alimentação infantil, temos acompanhado a pouca ingestão de produtos naturais e o aumento da preferência por produtos industrializados, como salgadinhos, sucos de caixinha e doces. Acreditamos que tal predileção é construída, principalmente, pela mídia e a associação empreendida entre fabricantes de alimentos e indústria do entretenimento infantil. Assim, o achocolatado, o salgadinho, a gelatina, os iogurtes e uma infinidade de produtos estampam nas caixas e embalagens os personagens conhecidos pelas crianças, seja por meio de desenhos, filmes ou jogos infantis.

Frente a esse panorama, o objetivo desse texto é problematizar a relação entre mídia, consumo e alimentação infantil, buscando reconhecer quais as preferências das crianças e como elas orientam suas escolhas alimentares. A partir das reflexões de autores como Horn (2016), Schor (2009) e Baader (2013), dentre outros, fizemos uma coleta de dados por meio de entrevista com grupos de crianças em idade escolar, a partir de um roteiro semiestruturado. Nesse sentido, em um primeiro momento refletimos brevemente sobre a relação dos sujeitos com a alimentação, em especial as crianças. Em seguida, problematizamos como a publicidade e as indústrias têm estimulado o consu- 
mo de determinados alimentos, pensando sobre suas estratégias e possíveis impactos nas escolhas das crianças. Num terceiro momento, a partir dos dados da pesquisa empírica, identificamos as preferências alimentares das crianças e discutimos como isso tem constituído a infância.

\section{Os seres humanos e sua relação com a alimentação}

Cavallini e Tedeschi (2006, s.p.) são enfáticas ao afirmar que a comida representa uma linguagem, com significado único para a espécie humana: "Todos os seres humanos, e em particular as crianças que estão em contínuo crescimento, têm uma relação vital com a comida. Porém, a comida não é somente alimento, é também uma linguagem, um verdadeiro alfabeto com o qual construímos a nossa relação com os outros e com o mundo".

Horn (2016) argumenta que a alimentação deve estar relacionada ao bem-estar das crianças, proporcionado prazer e aprendizagens. Se não pensarmos no ato de alimentar-se como pedagógico, podemos deixar de atentar para as ações e os encaminhamentos que dele fazem parte. Por isso, a importância de discutir o cuidado e a ética com a alimentação das crianças, pois esse momento promove um encontro social e afetivo que nos nutre como seres humanos. Essa concepção ganha especial sentido para problematizarmos a relação entre mídia, consumo e alimentação infantil, foco desse texto.

Contraditoriamente, na atualidade vivemos em um cenário onde muitas pessoas passam fome, ao mesmo tempo em que uma tonelada de alimentos é diariamente desperdiçada. Em alguns países a falta de alimentos mata diariamente pessoas, enquanto noutros as pessoas enfrentam constantemente desafios para manter o peso ideal. Esse contexto de desigualdade social não aparece na mídia, principalmente televisiva, quando da veiculação da publicidade de alimentos dirigidos ao público infantil. Crianças felizes, fascinadas pelos personagens que via de regra aparecem nas embalagens dos produtos, apresentam um contexto repleto de 'gostosuras' pensadas especialmente para os pequenos. No Brasil, não temos uma regulação efetiva dedicada à publicidade infantil, o que inclui o setor de alimentos.

É possível observar no mundo hodierno as transformações na vida familiar que remodelam, dentre vários aspectos, os hábitos alimentares. Assim, muitas famílias por falta de tempo ou por praticidade realizam as refeições fora de casa, fato que, em alguns casos, contribui para má alimentação, pois quase sempre as opções feitas são por alimentos menos saudáveis, ricos em 
gordura e açúcares. Observa-se um paradoxo no qual a desnutrição, ainda relevante, vem diminuindo, e a obesidade e problemas a ela relacionados, vem aumentando. Isto ocorre em parte devido à mudança nos padrões alimentares da população (TORRES et al., 2006).

Segundo a Organização Mundial da Saúde (OMS) a obesidade é uma pandemia que pode ser agravada com o surgimento de outras doenças, como diabetes, hipertensão, problemas respiratórios, apneia do sono e depressão. Como o número de crianças obesas vem crescendo a cada ano, reconhecemos uma infância que nem sempre é feliz e livre de preocupações. A visão romântica de infância, construída e consolidada na modernidade e por vezes ainda com crédito se depara com problemas enfrentados pelas crianças que até pouco tempo eram exclusivos do mundo adulto. Para Marcondes et al. (2003, p. 359):

A obesidade é uma condição clínica caracterizada pelo acúmulo excessivo de gordura no organismo, causando prejuízos à saúde. É considerada uma doença genética, multicausal, na qual interagem fatores ambientais, psicossociais, culturais, hereditários, alimentares, hormonais e metabólicos, resultando em balanço energético no qual a retenção crônica é maior que a diária.

Embora as predisposições genéticas não possam ser ignoradas, a reflexão sobre os impactos das escolhas alimentares, nesse artigo, considera como determinantes os fatores sociais e culturais que instauram uma pedagogia que ensina coisas às crianças. Isso porque no imaginário infantil se é emocionante assistir o filme dos Super Heróis, muito bom deve ser comer o alimento dentro da embalagem em que eles aparecem.

Hall (2011) enfatiza que o estilo de vida e os fatores ambientais contribuíram para o aumento da obesidade nas últimas décadas. Sendo assim, podemos dizer, que os hábitos alimentares são o reflexo dos valores sociais, econômicos e culturais instaurados na nossa era e muitas vezes naturalizados.

Sobre essa questão Cavallini e Tedeschi (2016, s.p.) apresentam interessante constatação: 
Nas cidades, tanto as crianças quanto os adultos não têm mais o conhecimento da origem dos alimentos (comida e água), razão pela qual podem deixar de apreender seu significado e valor. A verdadeira participação nos segredos da transformação da comida, esse processo que encanta, geralmente é esquecida por falta de tempo, de confiança e de cultura.

Nesse sentido, o cotidiano atribulado acaba sendo inundado pelos apelos da publicidade e suas inúmeras ofertas de produtos, inclusive alimentícios. Franco (2004, p.25) entende que "[...] os homens comem como a sociedade os ensinou [...], sendo que os hábitos alimentares decorrem da interiorização, desde a mais tenra infância, de regras e de restrições". Ou, no caso dos apelos da mídia, dos estímulos visuais e apelos verbais que constroem as propagandas de alimentos infantis.

Também não se pode deixar de mencionar as dificuldades que os pequenos encontram em seguir uma dieta alimentar pois, quase sempre, o desejo pelo alimento é maior que o bom senso.

O que fazemos hoje afeta nosso comportamento amanhã. Existe o problema do paladar infantil para quem nunca foi exposto a alimentos saudáveis e que não desenvolveu, portanto, o gosto pelo sabor natural. A introdução de alimentos não saudáveis, mesmo eventualmente, pode comprometer a capacidade de manutenção de uma dieta salutar no futuro (SCHOR, 2009, p.196).

No poema "Coração guloso" (RIBEIRO, 2006, p.12), a barriga ganha voz e fala com João. O poeta, ao brincar com as palavras, retrata a dificuldade encontrada muitas vezes em controlar-se durante os momentos de alimentação:

A barriga do João roncou, assobiou e rodopiou.

João mandou comida e a barriga voltou a roncar, assobiar e rodopiar.

João perguntou pra barriga: - Quer mais comida?

A barriga respondeu: - Não sou eu, João!

É o seu coração guloso que quer provar um abraço cremoso um afago carinhoso.

No diálogo de João com sua barriga é possível perceber que, muitas vezes, não nos alimentamos pela necessidade fisiológica da fome, mas pelos apelos da mídia que mexem com os sentimentos gerando, em alguns casos, a compulsão alimentar. 
Comendo com os olhos: estratégias para a educação dos sentidos e construção dos desejos

Schor (2009) reconhece que as crianças fazem parte do sistema capitalista de consumo desde que ele foi empreendido, em especial no século XX, incluindo o consumo dos produtos alimentícios. No documentário"Criança e consumo: transtornos alimentares e obesidade infantil" desenvolvidopelo Instituto Alana (2009), José Augusto Taddei menciona que se o ritmo se mantiver, as projeções para o ano de 2016 indicam que a obesidade atingiria 8,3\% das crianças, resultando em 1,5 milhão de crianças menores de cinco anos obesas.

Foucault (2002) nos ajuda a entender o discurso como verdade, como exercício do poder, que nos objetiva e interpela. Nessa compreensão, torna-se importante reconhecer de onde provêm os dizeres que orientam a alimentação infantil, instituem desejos e conformam as 'preferências' dos pequenos.

Nos dias atuais os mercados, panificadoras, restaurantes, as redes de fast food, oferecem muitas opções de alimentos e espaços próprios para o público infantil, o que revela que tanto a indústria quanto o setor de serviços e comércio buscam atrair as crianças para o consumo. Para isso, uma das principais estratégias de vendas é a forte presença dos personagens de desenhos animados nas embalagens e nas propagandas, aproximando-se do universo infantil já conhecido e divulgado pela indústria de entretenimento.

A associação entre as grandes corporações se estende para o ramo alimentício, visando o lucro, e embora seja um fenômeno socialmente construído está naturalizado, ou seja, a maioria dos consumidores adultos, provedores dos alimentos às crianças não manifesta qualquer estranhamento com a existência da ostensiva publicidade infantil de alimentos. Schor $(2009$, p.11) lembra que "Os publicitários têm acesso direto às crianças porque elas assistem televisão sem a presença dos pais", ou seja, as peças publicitárias falam com as crianças diariamente e de forma direta, com cores e sons atrativos que conquistam a atenção.

$\mathrm{Na}$ maioria das vezes, os alimentos propagandeados apresentam pouco ou nenhum valor nutritivo trazendo, sobretudo, grande teor de açúcar, sal e outros aditivos alimentares. A partir de composição muito bem planejada esses alimentos são geralmente saborosos e atrativos para as crianças, mas podem causar uma série de prejuízos à saúde.

Outra estratégia de divulgação e venda são os brindes vinculados aos produtos alimentícios, que juntamente com as embalagens atuam no sentido de conquistar as crianças. Baader (2013) mencionaque as empresas que 
utilizam dessas estratégias contam com o sucesso pelo fato de que além dos seus efeitos lúdicos, a criança leva para casa um brinde imediato e palpável.

A publicidade televisiva também tem uma forte influência na escolha dos alimentos pelo público infantil, porquemuitas vezes ensina as crianças a convencer seus pais a comprarem os produtos anunciados. Schor $(2009, \mathrm{p} .64)$ revela que "[...] o tempo de exposição à televisão é correlacionado positivamente com a solicitação. Os anúncios de alimentos afetam as preferências", ou seja, as propagandas são efetivas em criar disposições e solicitações de compra.

Segundo Moreno (1992), a televisão é um dos passatempos prediletos das crianças, sendo que as mesmas assistem em média de três a quatro horas por dia, com exposição sem precedente aos comerciais. Esse dado ainda piora quando algumas famílias permitem que as crianças realizem as principais refeições em frente à televisão, dificultando a rotina dos horários de alimentação e fazendo com que não seja percebida a quantidade alimento que a criança consome.

Schor (2009) registra que as grandes indústrias de alimentos têm investido esforços para barrar as tentativas de regulação da publicidade infantil e tentando mudar o foco da discussão sobre alimentação para a necessidade de exercício físico como forma de manter a saúde.

\section{Fisgados pela boca: quando o personagem 'vende' o produto e atua na for- mação da criança}

A fim de reconhecer as preferências alimentares e como se dão as escolhas das crianças diante dos alimentos que consomem, nos propusemos a coletar informações por meio de entrevista, que se desenrolou em forma de conversa. Kaufman (2013) nomeia essa forma de coleta de dados de entrevista compreensiva, sendo a forma mais adequada quando os sujeitos participantes são crianças, pois permite uma proximidade maior entre os sujeitos e estabelece-se uma relação de confiança entre entrevistado e pesquisador.

Foram ouvidas 27 crianças, com idade entre 6 a 8 anos, que são alunos do primeiro ao terceiro ano do ensino fundamental de duas instituições de ensino do município de Guarapuava (Paraná), no primeiro semestre do ano de 2016. A seleção das instituições deu-se de forma aleatória, bem como a participação das crianças que foi motivada pela livre manifestação e autorizada por seus responsáveis. Para efeitos de análise, omitimos a identificação das instituições e optamos por manter o verdadeiro nome das crianças, entenden- 
do-as como sujeitos principais da pesquisa (KRAMER, 2002). Preliminarmente, foram realizadas visitas às duas escolas com o intuito de conhecer as instituições, conversar com a equipe pedagógica e deixar o Termo de Consentimento Livre e Esclarecido para que fosse enviado aos responsáveis pelas crianças.

As conversas foram gravadas e posteriormente transcritas com a finalidade de focalizar as crianças e dar importância às suas vozes, pois como registra o Kaufmann(2013, p.79), “[...] o desafio é superar uma análise superficial, ou pautar-se apenas no que está explícito e aparente". O autor ainda ressalta que "[...] para atingir as informações essenciais, o pesquisador deve se aproximar, de fato, do estilo da conversa [...]" (p. 79) dos sujeitos. Os encontros aconteceram na parte externa das instituições, local no qual as crianças sentaram em círculos, em pequenos grupos.

Alessi (2014) ressalta que muitos estudiosos e pesquisadores têm se preocupado em que as crianças tenham vez e voz na coleta de dados, sendo importante dedicar um tempo para escutá-las e considerá-las como informantes competentes acerca do mundo que as cerca e das relações que estabelecem.

Apresentamos brevemente algumas informações das instituições frequentadas pelas crianças participantes da pesquisa. A primeira instituição (A) é uma escola privada que atende 191 crianças de educação infantil e ensino fundamental I e II, em jornada parcial ou integral. Dispõe de boa estrutura física, inclusive com uma horta na qual, de acordo com a equipe pedagógica, são realizados projetos voltados à alimentação. Durante a concretização desses projetos os alunos plantam, cuidam da horta, colhem e levam para casa os alimentos por eles cultivados. As mesmas verduras e legumes também são preparados para o almoço das crianças que frequentam período integral. Além da horta, a escola oferece uma trilha ecológica e um espaço externo amplo no qual acontecem aulas de equitação. Asegunda instituição (B)estálocalizada naperiferia da cidade e atende 254 alunos matriculados no período matutino e vespertino. A escola é ampla, as salas são confortáveis e o espaço externo é grande.

Quanto às crianças, nas duas instituições elas mostraram-se receptivas e animadas com a realização da entrevista. Embora tivéssemos distribuído mais de 120 Termos de Consentimento Livre e Esclarecido para as crianças, apenas 27 retornaram assinados, representando os entrevistados participantes desse estudo.

Partimos do pressuposto de que para reconhecer os hábitos alimentares das crianças precisávamos dedicar um tempo para escutá-las, pois entendemos que elas 
[...] sabem muito e sobre muitas coisas. Muitas vezes, são saberes diferentes dos do adulto-professor, mas que possuem seu valor, o seu sentido e que variam em função das relações estabelecidas por elas nos espaços sociais, históricos e culturais em que vivem. Precisamos de sensibilidade e escuta atenta [...] (ALESSI, 2014, p.185).

As falas foram organizadas a partir da apresentação de alimentos e produtos, bem como de imagens ${ }^{4}$. Num primeiro momento, mostramos figuras de alimentos cuja embalagem estampava personagens conhecidos pelas crianças por sua veiculação em desenhos e filmes, como Galinha Pintadinha, Snoopye Minions, os quais fazem parte da atualidade dos desenhos infantis e são conhecidos pelas crianças, e outros alimentos com embalagens sem personagens.

Inicialmente apresentamos imagens do produto leite fermentado com e sem personagem; segue o diálogo:

Pesquisadoras: Quando vocês vão ao supermercado com seus familiares quais dos dois produtos vocês preferem/compram? Crianças: $O$ da galinha pintadinha (em coro).

Pesquisadoras: Por que escolhem esse, é o mais gostoso?

Crianças: Nãaao (prolongamento de vogal).

Pesquisadoras: Então por que preferem esse?

Gabrielly: Eu prefiro o da galinha pintadinha porque é de criança. Pesquisadoras: E o personagem está aqui por causa da criança ou do adulto?

Crianças: Das crianças.

Pesquisadoras: Por que?

Maria Eduarda: Pra deixar as crianças mais alegres.

Eduardo: Porque faz parte da infância da criança. (INSTITUIÇÃO A).

Observamos na conversa a identificação criada entre o produto que trazia o personagem do desenho infantil conhecido por eles, no caso, a galinha pintadinha. Reconhece-se, portanto, que a relação entre esse alimento e as crianças foi fortalecida pelo personagem. Galindo (2008, p.10) afirma que:

[...] a ideia de proporcionar entretenimento no ato de consumir um produto alimentício torna-se ainda mais atraente quando

${ }^{4}$ Tal encaminhamento foi inspirado no documentário Muito além do peso (2012), de Estela Renner. 
envolve um personagem que faz parte do cotidiano das crianças e que é admirado por elas, um herói da televisão, por exemplo.

$\mathrm{Na}$ instituição B mostramos figuras de bebida láctea, uma da marca Choco Milk e a outra com a figura dos Minions. Novamente perguntamos qual preferiam, e a maioria optou pelo produto que estampa o personagem; apenas Nicole disse que "Compraria o outro porque não gosto dos Minions e nem assisto ele na TV".

Percebemos que a escolha dos produtos está relacionada à utilização, como recurso apelativo, de personagens do universo infantil na publicidade de diferentes marcas. Assim, a associação entre produtos e bens culturais (filmes, desenhos animados, livros) que configuram gostos e determinam preferências, contribui para o aumento das vendas e empatia da marca perante o público infantil, e isso é um fato que merece a devida atenção, principalmente por se tratarem de alimentos de baixo valor nutricional.

Em outro momento, mostramos a figura de uma lata de Coca-Cola e perguntamos:

\author{
Pesquisadoras: Quem gosta de Coca-Cola? \\ Crianças: Euuuuuu (em coro). \\ Pesquisadoras: vocês tomam Coca-Cola todos os dias? \\ Ana Flávia: Posso tomar somente no final de semana. \\ Ana Júlia: nem sempre \\ Emily: Minha mãe não deixa eu tomar todo dia. \\ Gabriel: Eu tomo, mas não todo dia. \\ Pesquisadoras: Vocês acham que o refrigerante é feito com \\ açúcar? \\ Crianças: Sim \\ Pesquisadoras: Bastante ou pouco? \\ Crianças: Pouco \\ (INSTITUIÇÃO B).
}

Observamos, pelas falas das crianças, que todas disseram gostar do refrigerante, embora não possam tomar todos os dias. As propagandas veiculadas na mídia pela marca associam o consumo à ideia de felicidade, sem mencionar restrições ou mesmo a composição do refrigerante, que leva muito açúcar e corante. Segundo Schor (2009), os estudos indicam que o consumo de refrigerantes por crianças aumentou muito nos últimos dez anos, sendo que estimativas indicam que mais da metade das calorias ingeridas por crianças 
norte-americanas vem das bebidas industrializadas.

Em seguida, ao mostrarmos a figura de um combo (lanche, batatas e refrigerante) do Bob's perguntamos o que as crianças entrevistadas achavam daquele alimento:

Luiza: Uhum.

Eduardo: Ai, ai! Que delícia! Quando eu olho, dá vontade de comer.

João Victor: O mais legal é o brinquedo que vem dentro do lanche. Raíssa: Eu adoro quando é sábado, e eu posso ir ao Bob's.

Helena: Tem o parquinho

(INSTITUIÇÃO A).

As crianças evidenciam que gostam de frequentar o Bob's, pois, além dos lanches que vêm com brinquedos de personagens conhecidos, esses ambientes contam com um espaço específico para elas brincarem. Assim, entram em cena os parques, mesas para desenhos, salas de jogos, cantinhos da leitura e contação de histórias. Tais estratégias conquistam as crianças enquanto consumidoras de alimentos e associam a marca e o espaço ao lazer e à diversão, o que leva a criança a querer voltar mais vezes.

Perguntamos para as crianças das duas instituições se elas costumam ir com seus pais ao supermercado, e todas afirmaram que sim. Nesse espaço, mais do que acompanhantes dos adultos, as crianças expressam gostos, influenciam escolhas e encontram produtos e gôndolas especialmente pensadas para elas.

Pesquisadoras: Quando vocês vão com seus pais no supermercado o que costumam comprar?

Alice: Eu gosto de comprar salgadinhos.

Eduardo: Eu chocolate, muitos doces.

Maria Eduarda: Eu bolacha recheada

(INSTITUIÇÃO A).

Pesquisadoras: E quando vocês passam nas gôndolas em frente aos caixas do supermercado, vocês têm desejo pelos produtos ali expostos?

Gabriel: Muito, eu sempre quero comprar Kinder Ovo, mas meu pai não deixa comprar, porque é muito caro.

Maycon: Eu compro sempre chocolates, minha mãe deixa.

Pesquisadoras: Os pais deixam vocês comprarem tudo que vocês 
desejam?

Grazielly: Minha mãe deixa eu comprar só uma coisa.

Erica: Minha mãe faz combinado em casa, só duas coisas.

Nicole: Eu tenho um irmão, então minha mãe deixa eu comprar duas coisas, uma para mim e outra para meu irmão".

Nicolas Eduardo: Eu sempre pego vários (INSTITUIÇÃO B).

Assim, os supermercados, ao colocarem os alimentos como doces e bebidas na altura das crianças, estão estrategicamente traçando uma medida apelativa de consumo, que exige, por parte dos pais, uma contínua negociação com os pequenos, induzidos a quererem tudo, seduzidos pelas cores e desenhos das embalagens. De acordo com Brito (2009), as crianças são consideradas há muito tempo consumidoras, pois impõem seus desejos aos pais e acabam influenciando nos momentos das compras domésticas.

Havíamos levado também para as crianças alguns legumes, como abobrinha, berinjela, beterraba, brócolis, cenoura, chuchu e pepino, com o intuito de verificar se faziam parte da sua alimentação e se eram por elas conhecidos. Os alunos da instituição $A$ reconheceram os alimentos e relataram que fazem o consumo em casa, sendo que somente a berinjela foi 'rejeitada' por eles. As crianças da instituição B identificaram apenas os brócolis, a cenoura e o pepino. A grande maioria afirmou consumir em casa somente brócolis e cenoura. Assim, observamos que uma parte das crianças conhece e consome legumes e a outra parcela delas não tem hábito alimentar que os inclui, inclusive não consegue nomeá-los. Vale lembrar que a instituição A possui um projeto alimentar e conta com uma horta, onde os alimentos são plantados e colhidos pelas próprias crianças e consumidos na escola e em suas casas. Ressaltamos a importância de trabalhos nessa direção que buscam apresentar, esclarecer e envolver as crianças em práticas de alimentação saudável.

Por fim, buscamos reconhecer como se manifesta para as crianças a relação entre mídia, personagens e consumo:

Pesquisadoras: Quando vocês visualizam algum personagem na televisão e depois vêm o mesmo personagem na embalagem de algum alimento no supermercado, vocês sentem vontade de comprar?

Crianças: Sim.

Maria Cecília: Sempre que eu assisto as propagandas da CocaCola eu quero tomar e vem aquele gostinho na minha boca.

Luis Felipe: Eu compro e quando eu gosto muito, eu deixo ali e 
fico só olhando, depois de um tempão que eu como (INSTITUIÇÃO A).

Como registra Dornelles (2005, p. 95) as "[...] crianças consomem com os olhos, absorvendo produtos com o olhar cada vez que empurram o carrinho pelos corredores de um supermercado, navegam na internet e assistem televisão [...]". Luis Felipe, a criança acima, nos conta que o fascínio exercido pelo produto é intenso e que a possibilidade de o admirar lhe traz satisfação.

As falas das crianças e suas manifestações corporais evidenciadas durante a conversa revelam a estreita relação das crianças com os produtos, os personagens e o consumo. Com imagens que enchem os olhos e conquistam as crianças, os desejos são construídos na articulada associação entre publicidade, indústria de alimentação e corporações voltadas ao entretenimento infantil.

\section{Considerações finais}

A problematização da relação entre as crianças, o consumo e a alimentação já foi empreendida por outros autores, mas ainda não está suficientemente esgotada haja vista que a publicidade infantil no Brasil não tem regulação. Nesse contexto, percebemos o quão incisiva é a abordagem do marketing para com as crianças, convocando-as a provarem, comprarem e convencerem os adultos para adquirir tais produtos.

O campo do entretenimento infantil muitas vezes não é olhado com a devida atenção, pois predomina a visão de que se refere à diversão, ao prazer, como algo inofensivo. Contudo, no caso da alimentação infantil, quando os fabricantes associam os produtos aos personagens que dialogam direta e diariamente com as crianças por meio dos filmes e desenhos animados estabelecese uma intenção de convencimento que acaba levando as crianças a fazerem escolhas que comprometem sua saúde, uma vez que em geral são produtos com pouco valor nutritivo. As falas das crianças nos mostraram que escolhem os produtos que têm os personagens nas embalagens; em outras palavras, indicaram que se sentem fascinadas e comem 'com os olhos e com a boca'.

Frente a esse panorama torna-se urgente pensar sobre esses aspectos e conversar com as crianças ajudando-as a perceber e selecionar melhor os alimentos que consomem, estimulando a conscientização por meio de práticas que tenham essa temática como centro do processo de ensino, tanto no nível diário como a médio e longo prazo. 


\section{Referências}

ALESSI, V. M. Rodas de conversa: uma análise das vozes infantis.Curitiba: UFPR, 2014.

BAADER, C. Alimentação ou diversão? A publicidade contemporânea de alimentos infantis e suas possibilidades de sentidos para as práticas de consumo e hábitos alimentares das crianças. Dissertação de Mestrado, 352 p.Programa de Pós-Graduação em Ciências da Comunicação - Escola de Comunicação e Artes, 2013.

BRITO, I. M.C. A influência da publicidade na alimentação infantil. Fortaleza; Faculdade Católica do Ceará, 2009.

CAVALLINI, I.; TEDESCHI, M. A comida e suas linguagens. Pátio Educação Infantil, Porto Alegre, n.47, abril 2016. Disponível em: www.loja.grupoa.com. br/revista-patio. Acesso em: 30 nov. 2016.

DORNELLES, L. V. Infâncias que nos escapam. Da criança na rua à criança cyber. Petrópolis, RJ: Vozes, 2005.

FRANCO, A. De Caçador a Gourmet. São Paulo: editora Senac, 2004.

FOUCAULT, M. A ordem do discurso. São Paulo: Loyola, 2002.

GALINDO, D.; ASSOLINI, P. J.Eatertainment: a divertida publicidade que alimenta o público infantil. 2008. Anais do 11 을 Congresso Latino Americano de Investigadores de la comunicación, Cidade do México, 2008.

HALL, J. E. Tratado de Fisiologia Médica. 12. ed. Rio de Janeiro: Elsevier; 2011.

INSTITUTO ALANA. Projeto Criança e Consumo. Entrevistas: Transtornos Alimentares e Obesidade Infantil, 2009. Disponível em: http://criancaeconsumo.org.br/wp-content/uploads/2014/02/Crian\%C3\%A7a-e-Consumo-Entrevistas-Vol-3.pdf. Acesso em: 30 nov. 2016.

HORN, M. da G. S. A ética e o cuidado com a alimentação na escola infantil. Pátio Educação Infantil, Porto Alegre, n.47, abril 2016. Disponível em: www. loja.grupoa.com.br/revista-patio. Acesso em: 30 nov. 2016.

KAUFMANN, J. C. A entrevista compreensiva: um guia para pesquisa de campo. Petrópolis/Maceió, Vozes/Edufal, 2013.

KRAMER, S. Autoria e autorização: questões éticas na pesquisa com crianças. Cadernos de pesquisa,São Paulo, n. 116, p. 41-59, julho 2002. 
MARCONDES, E. de et al. Pediatria básica: pediatria Clínica Geral. tomo II- 9 ed. São Paulo: Sarvier, 2003.

MORENO, L. K. Televisão: a babá nossa de cada dia.Jornal da USP, São Paulo, p. 6, 9-15 mar. 1992.

PIOTTO, D. C.; FERREIRA, M. V.; PANTONI, R. V. "Comer, comer... comer, comer... é o melhor para poder crescer...". In: ROSSETTI-FERREIRA, M. C. et al. (Orgs.). Os fazeres na educação infantil. São Paulo: Cortez, 2016.

RENNER, Estela. Documentário Muito além do peso, 2012. Disponível em: https://www.google.com.br/search?q=muito+alem+do+peso\&spell=1\&sa=X\&ved=0ahUKEwj8xc_y2trWAhUJvZAKHevGACgQvwUIJCgA\&biw=1366\&bih=637. Acesso em: 05 out. 2017.

RIBEIRO, J. Poesias de dar água na boca. II. André Neves. São Paulo: Ave-Maria, 2006.

SCHOR, J. B. Nascidos para comprar: uma leitura essencial para orientarmos nossas crianças na era do consumismo. São Paulo: Gente, 2009.

TORRES, A.; FURUMOTO, R. A.; ALVES, E. D. A avaliação nutricional como estratégia para as ações de promoção à saúde no ambulatório de pediatria do Hub. Dissertação de Mestrado em Nutrição, Universidade de Brasília, 2006. 